\title{
Effect of vibration frequency on microstructure and performance of high chromium cast iron prepared by lost foam casting
}

\author{
Wen-qi Zou ${ }^{1,2}$, Zhi-guo Zhang ${ }^{1}$, Hao Yang ${ }^{1,3}$ and Wei Li ${ }^{1,3^{*}}$ \\ 1. Department of Materials Science and Engineering, Jinan University, Guangzhou 510632, China; \\ 2. Guangdong Dongguan Quality Supervision Testing Center (National Mould Products Quality Supervision Inspection Center), Dongguan 523808, China; \\ 3. Shaoguan Research Institute, Jinan University, Shaoguan 512027, China
}

\begin{abstract}
In the present research, high chromium cast irons ( $\mathrm{HCCls}$ ) were prepared using the lost foam casting (LFC) process. To improve the wear resistance of the high chromium cast irons (HCCls), mechanical vibration was employed during the solidification of the $\mathrm{HCCls}$. The effects of vibration frequency on the microstructure and performance of the $\mathrm{HCCls}$ under as-cast, as-quenched and as-tempered conditions were investigated. The results indicated that the microstructures of the LFC-produced $\mathrm{HCCls}$ were refined due to the introduction of mechanical vibration, and the hardness was improved compared to that of the alloy without vibration. However, only a slight improvement in hardness was found in spite of the increase of vibration frequency. In contrast, the impact toughness of the as-tempered $\mathrm{HCCls}$ increased with an increase in the vibration frequency. In addition, the wear resistance of the $\mathrm{HCCls}$ was improved as a result of the introduction of vibration and increased with an increase in the vibration frequency.
\end{abstract}

Key words: high chromium cast iron; vibration frequency; lost foam casting; microstructure; wear resistance

CLC numbers: TG143.9 Document code: A Article ID: 1672-6421(2016 04-248-08

L ost foam casting (LFC) is a relatively near-net shape and precision forming process. In this process, the foam polymer patterns with a desired shape are coated with refractory coatings, dried and then embedded into unbonded sands for vibration molding. When the molten metal is poured directly on the foam under negative pressure, the gas created by the vaporized foam pattern escapes through the coating and into the sand. Therefore, the liquid metal filled in the patterns forms a component of a desired shape ${ }^{[1-2]}$.LFC has been widely utilized to produce metal components thanks to its unique advantages such as high precision, three-dimension shape controllability, repeatability ${ }^{[3-4]}$. However, the poor heat transmission capability of the dried sand used in the LFC process leads to a relative lower cooling rate in solidification compared to traditional sand casting. As

\section{*Wei Li}

Male, born in 1963, Ph.D. Professor. His research interests mainly focus on abrasion metallic materials and metal matrix composites, special functional metallic materials, tribological research and biomedical materials.

E-mail: Iwxasn@sohu.com

Received: 2016-04-20; Accepted: 2016-06-20 a result, the mechanical performance and service life of the LFC-produced parts are compromised due to the presence of coarse grains and low density. Therefore, the issues on how to refine the microstructures of the LFC-produced metal components have been the center of attention through recent years ${ }^{[5-7]}$.

Mechanical vibration as a technique has been proven successful in the microstructure refinement of the casting components in recent years ${ }^{[8-10]}$. The beneficial effects include promotion of nucleation and thereby reduction of grain size and shrinkage porosities due to the improvement of the metal feeding effect and the formation of a more homogenous metal microstructure. All these are helpful in the reduction of residual stress, the enhancement of mechanical properties, and the improvement of wear resistance ${ }^{[8]}$. However, the lack of quantitative conclusive correlation between mechanical vibration parameters such as vibration mode and amplitude, as well as frequency and the resulting refinement, has prevented this technique from a more broad application. In particular, the effect of mechanical vibration frequency on the solidification behavior during the LFC process has not yet been studied in detail. Therefore, in the present study, the HCCIs were chosen 
due to their popularity in the wear resistant materials field ${ }^{[11-12]}$, and the effect was studied with the use of the constant amplitude of $0.32 \mathrm{~mm}$ in vertical vibration mode and variable frequencies.

\section{Experimental procedures}

\subsection{Materials, melting and casting}

HCCIs are often used to produce various wear resistant components in industrial applications such as mineral processing, cement manufacturing, slurry pumping and pulp and paper manufacturing industries ${ }^{[13-15]}$.

The HCCIs were melted in a medium-frequency induction furnace. After melting and deslagging, the molten liquid was poured using the conventional gravity poured lost foam casting process with vibration. The amplitude of vibration was fixed at $0.32 \mathrm{~mm}$ and the vibration frequencies were $0,30,40$ and $50 \mathrm{~Hz}$, respectively. Vibration began before pouring and stopped at 180 $\mathrm{s}$ after pouring. The vibration direction was perpendicular to the vibration generator. The chemical composition of the tested HCCI samples in the present work is shown in Table 1.

Table 1: Chemical composition of tested $\mathrm{HCCl}$ samples (wt.\%)

\begin{tabular}{ccccccccccccccc} 
C & Si & Mn & P & S & Cr & Mo & Ni & Cu & W & V & Ti & B \\
\hline 3.37 & 0.64 & 0.79 & 0.03 & 0.036 & 24 & 0.4 & 0.54 & 0.19 & 0.13 & 0.16 & 0.01 & 0.04
\end{tabular}

After solidification, a heat treatment cycle was employed for the test samples, which includes a quenching process and a tempering process. The detailed schematic of the heat treatment procedure is shown in Fig. 1.

\subsection{Metallography and mechanical property examination}

Specimens for microstructure observation were taken from the middle of the samples. When the sanding and polishing processes were finished, the specimens were etched using a solution of $4 \%$ nital. The microstructure observation was performed on a Leica (DMI3000) optical microscope. Rockwell hardness (HRC) tests were conducted and the hardness value average of three tests was recorded. Impact tests were carried out using a small pendulum impact testing machine (JB30A-30/15). The impact specimens were prepared with dimensions of $10 \mathrm{~mm}$ x $10 \mathrm{~mm}$ x $55 \mathrm{~mm}$ and with no notch, as shown in Fig. 2. Three specimens were measured to obtain an average value of impact absorption energy.

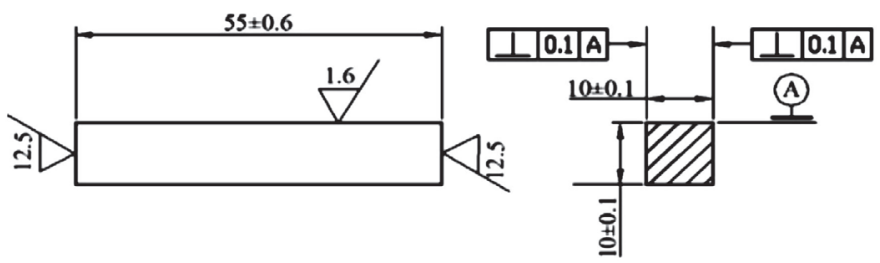

Fig. 2: Dimension of impact specimens with no notch

\subsection{Wear resistance evaluation}

The wear resistance evaluation for the LFC produced HCCIs was conducted using a MMH-5A type ring-to-block three-body abrasive wear testing machine. A schematic of the operational principle of the testing machine is illustrated in Fig. 3. Silica sands were utilized as an abrasive medium since they are the common natural hard abrasive material. The size of the abrasive grit was controlled by a sieve in the range of 60-80 meshes. A total weight of $4 \mathrm{~kg}$ of abrasive sand was used for each test.

The HCCIs specimens with a trapezoidal section were clamped in a holder and held rigidly against the rotating quenched 45\#

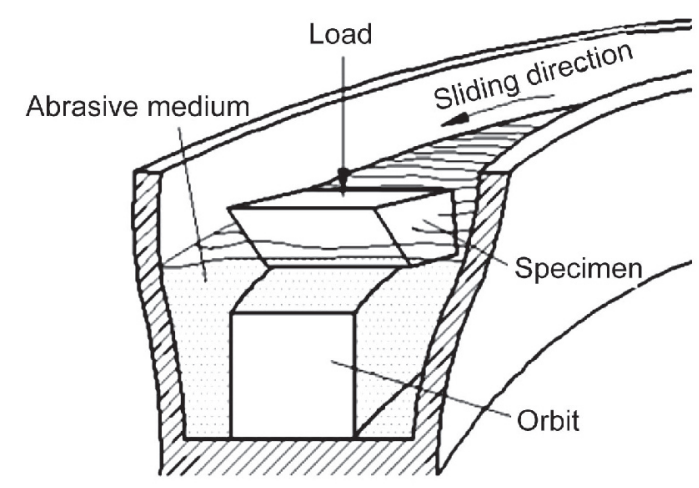

Fig. 3: A schematic on operational principle of three-body abrasive wear tester 
steel wheel of $360 \mathrm{~mm}$ in diameter under normal loads of 30 or $50 \mathrm{~N}$. The rotation speed of the specimens was $30 \mathrm{rpm}$. The sliding time for each test was $150 \mathrm{~min}$ after a 30 min runningin time. Every $30 \mathrm{~min}$, the specimens were taken out, cleaned in ethanol using an ultrasonic machine and then dried before weighing. Each specimen was weighed using a balance with an accuracy of $0.1 \mathrm{mg}$. The abrasive wear results were averaged over three samples for each condition.

\section{Experimental results}

\subsection{Effects of vibration frequency on microstructure and hardness of as-cast HCCls}

The as-cast HCCIs have hypereutectic compositions based on the $\mathrm{Cr} / \mathrm{C}$ ratio. Their microstructures mainly consist of primary carbides and eutectic colonies, which is quite similar to our previous study ${ }^{[12]}$. The primary carbides and the eutectic carbides are thought to be mainly $\mathrm{M}_{7} \mathrm{C}_{3}$ type when taking into account the $\mathrm{Cr} / \mathrm{C}$ ratio. The typical morphologies of the HCCIs under different vibration frequencies are presented in Fig. 4. The coarse strip and isotropic hexagonal primary carbides and the petal-like eutectic colonies occurred in the as-cast specimens without vibration, as shown in Fig. 4(a). The residual holes on the specimen surface were due to the peeling off of the brittle carbides during sample preparation. The eutectic colonies could be further divided into eutectic carbide and austenite (probably partially transformed to martensite at room temperature) with high alloy contents. With an increase in the vibration frequency, the primary carbides, especially the hexagonal primary carbides, were refined gradually and the shape of the primary
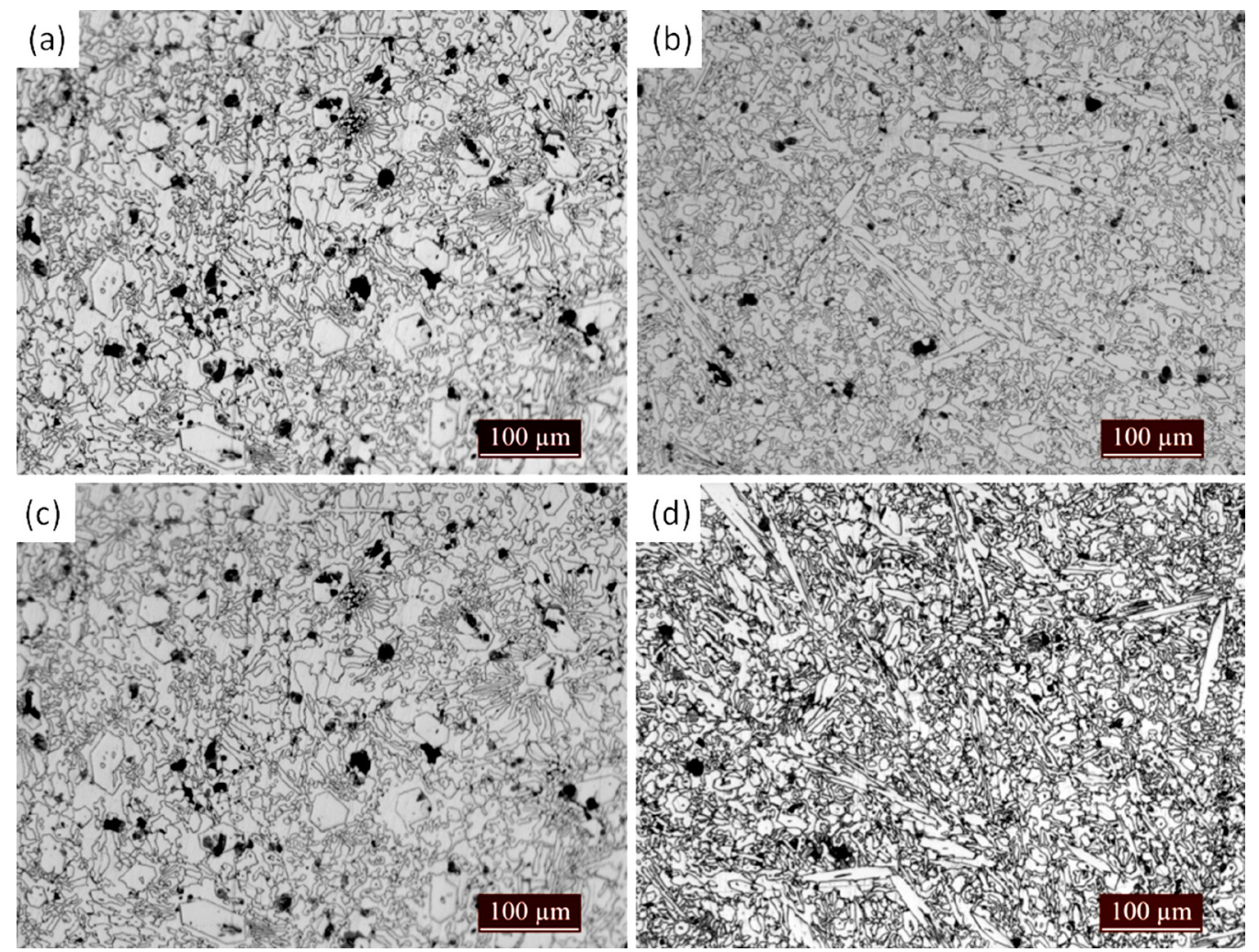

Fig. 4: Microstructure of the LFC produced HCCls under different mechanical vibration frequencies: (a) $0 \mathrm{~Hz}$; (b) $30 \mathrm{~Hz}$; (c) 40 $\mathrm{Hz}$ and (d) $50 \mathrm{~Hz}$

carbides became more isotropic. Correspondingly, the eutectic colonies were also refined. In particular, when the vibration frequency reached $50 \mathrm{~Hz}$, grain refinement became more evident as compared to the other specimens. Moreover, the reduction of holes could also be found for the specimen with a vibration frequency of $50 \mathrm{~Hz}$, which could attribute to the improvement of toughness resulting from the grain refinements.

The hardness evolution of as-cast HCCIs under various vibration frequencies is shown in Fig. 5. The specimen without vibration possessed an average hardness value of 58.1 HRC. This value demonstrates a slight increase with an increase in the vibration frequency. The maximum hardness of $60.4 \mathrm{HRC}$ was achieved, corresponding to the vibration frequency of $50 \mathrm{~Hz}$, which is approximately $2 \mathrm{HRC}$ higher than that of the specimen

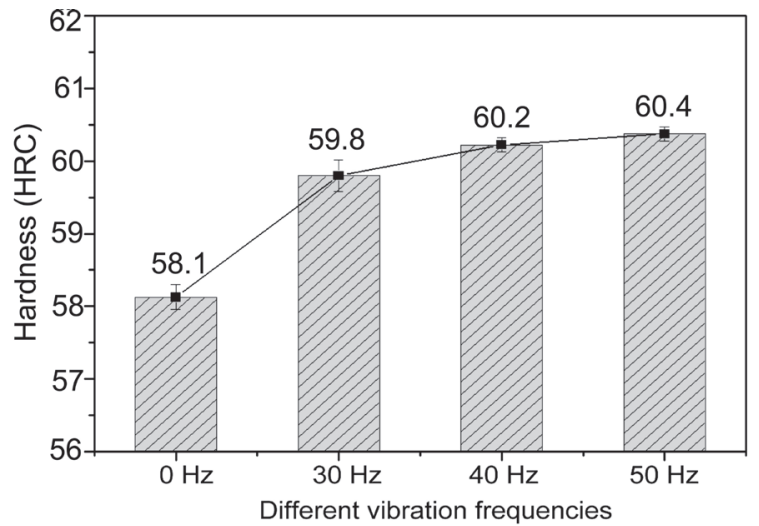

Fig. 5: Evolution of hardness of as-cast $\mathrm{HCCls}$ with different vibration frequencies 
without vibration.

\subsection{Microstructure and hardness of HCCls after quenching}

Figure 6 shows the microstructure of the asquenched HCCIs produced under different vibration frequencies. It can be found that the matrix in eutectic colonies is dark, suggesting the transformation from austenite to martensite. In addition, a great deal of secondary carbide particles can be observed, which were from the austenite destabilization at high temperature ${ }^{[16]}$. The primary carbides and the carbides in eutectic colonies remained almost unchanged compared to those in the as-cast specimens. The as-quenched specimens under mechanical vibration show quite similar microstructures in spite of the variation of vibration frequency.
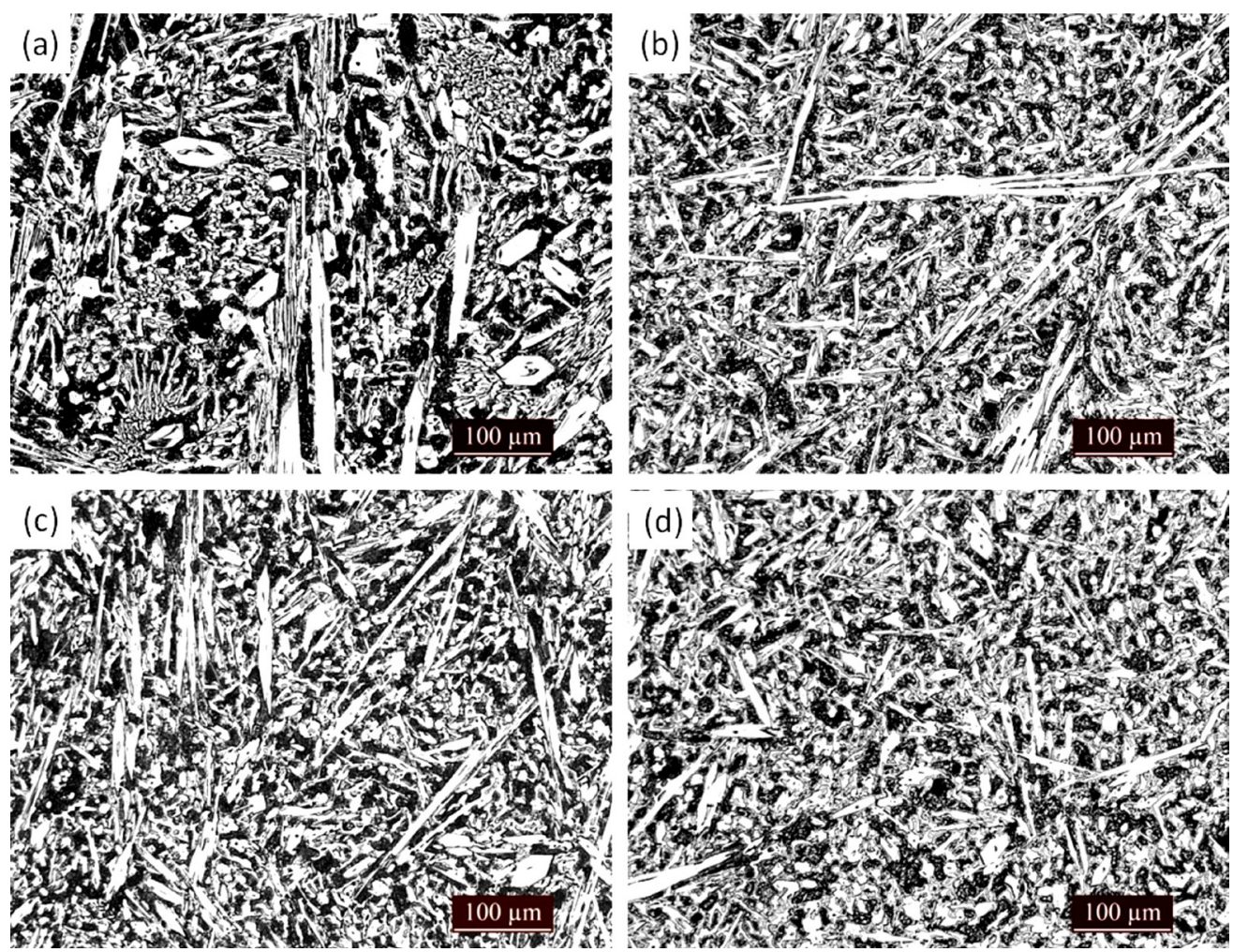

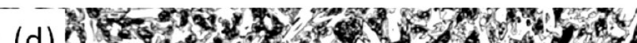
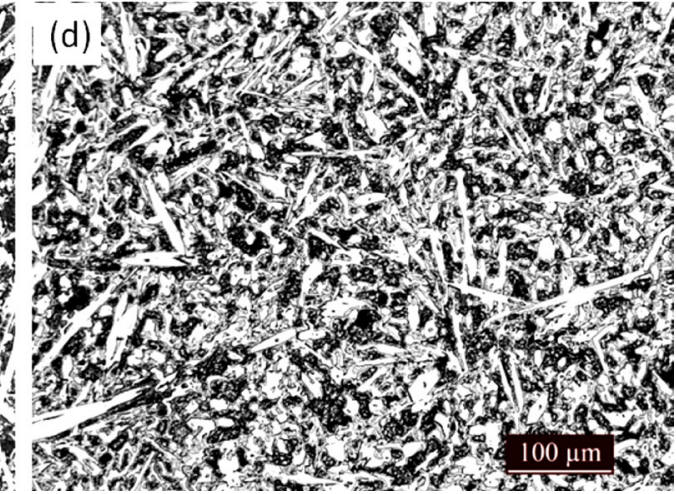

Fig. 6: Microstructure of as-quenched HCCls: (a) $0 \mathrm{~Hz}$; (b) $30 \mathrm{~Hz}$; (c) $40 \mathrm{~Hz}$ and (d) $50 \mathrm{~Hz}$

Figure 7 presents the hardness evolution of the as-quenched HCCIs with different vibration frequencies. It is found that the hardness for all the as-quenched specimens shows an increase in value of 7-8 HRC compared to the as-cast specimens, which is mainly due to the formation of the martensite and the destabilized secondary carbides. However, the variation of hardness was still not evident in spite of the increase of vibration frequency. This is probably due to their quite similar microstructure. The maximum hardness value is $67.4 \mathrm{HRC}$, corresponding to the specimen produced with a vibration frequency of $50 \mathrm{~Hz}$.

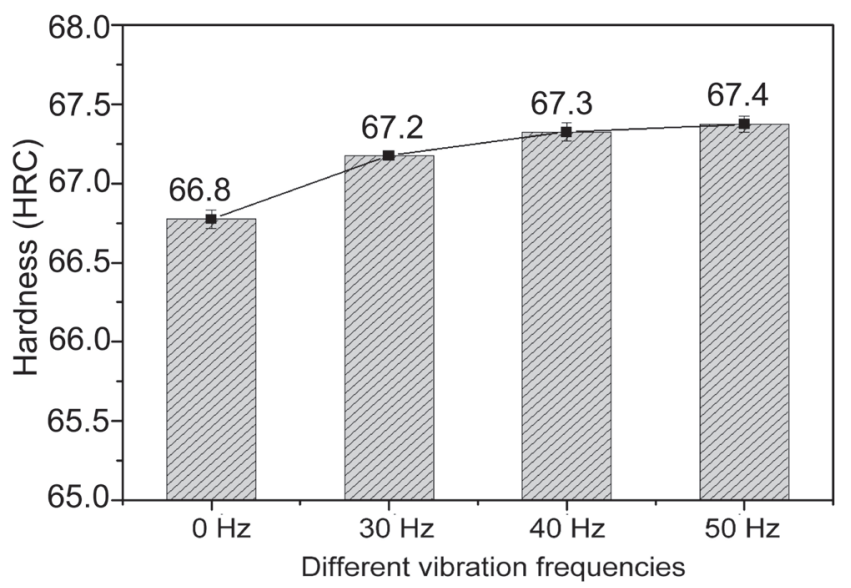

Fig. 7: Hardness of as-quenched HCCls

\subsection{Microstructure, hardness and impact toughness of $\mathrm{HCCls}$ after tempering}

Figure 8 presents the phase composition evolution for the typical samples under different treatment conditions. The sample was produced using a mechanical vibration frequency of $30 \mathrm{~Hz}$. It is shown that the as-cast sample was composed of $\mathrm{M}_{7} \mathrm{C}_{3}$ type

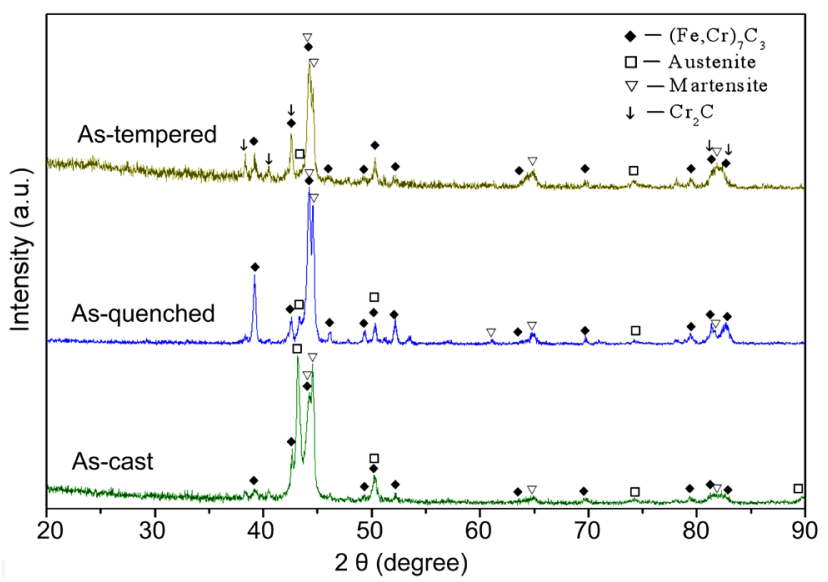

Fig. 8: X-ray diffraction patterns of typical $\mathrm{HCCl}$ samples produced using a mechanical vibration frequency of $30 \mathrm{~Hz}$ under different conditions

carbides, austenite and partial martensite. After quenching treatment, the relative intensity of austenite diffraction peaks was greatly weakened, suggesting that there was a transformation from austenite to martensite. Therefore, the asquenched sample was mainly composed of primary carbides, eutectic carbides, secondary carbides, martensite and retained 
austenite when taking into account the previous analysis in the microstructure of the as-quenched HCCIs. The tempering treatment led to the transformation of martensite to tempered martensite and some precipitated carbides distributed within the martensite. However, it is difficult to distinguish the tempered martensite from the quenched martensite in the XRD pattern.

The precipitated carbides should be $(\mathrm{Fe}, \mathrm{Cr})_{7} \mathrm{C}_{3}$ and $\mathrm{Cr}_{2} \mathrm{C}$.

The microstructures of the as-tempered HCCIs are shown in Fig. 9. The morphologies of the primary carbides and eutectic colonies show little change compared to those of the as-cast
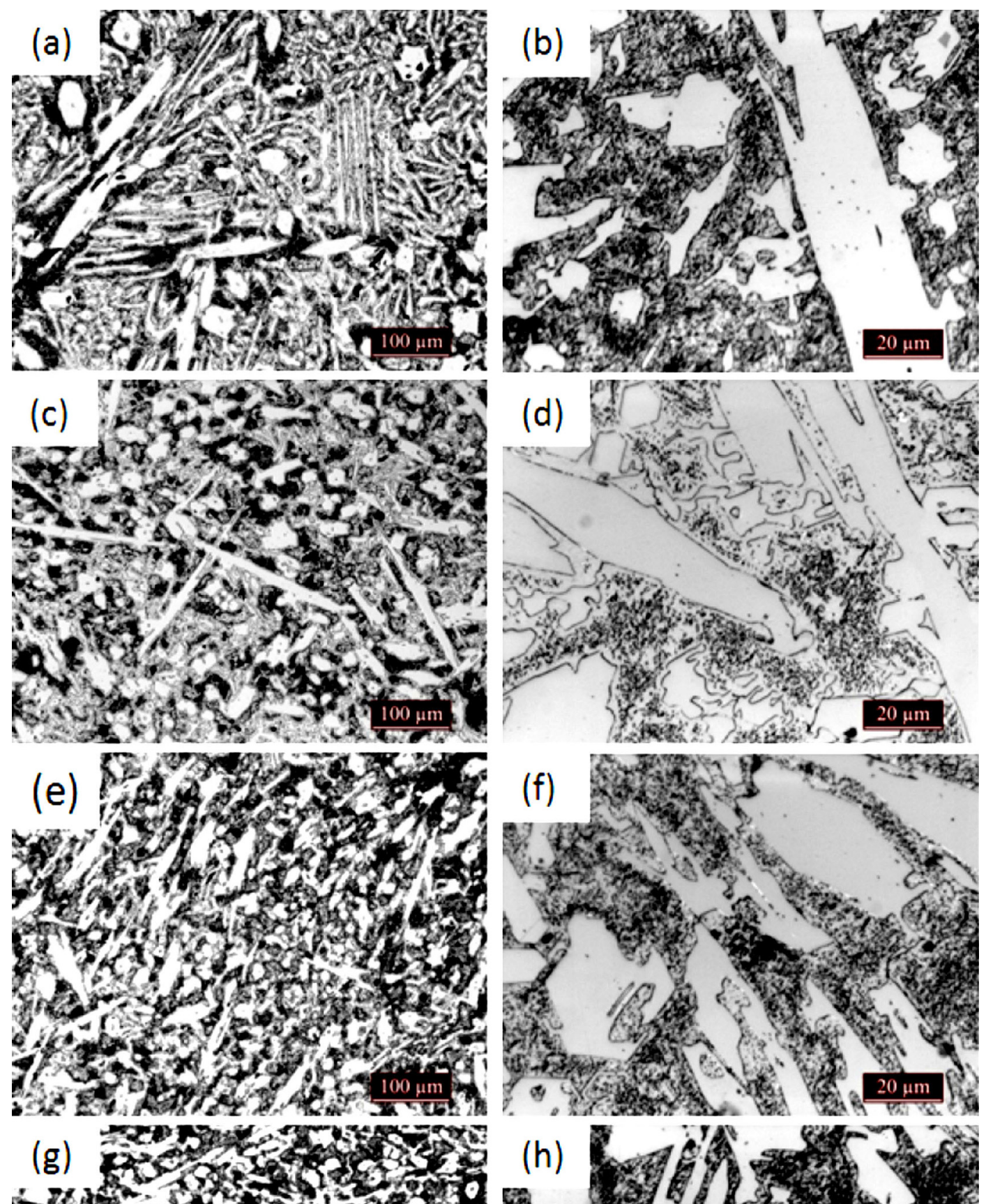

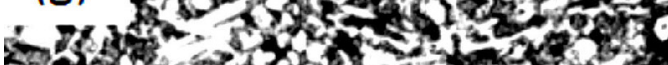
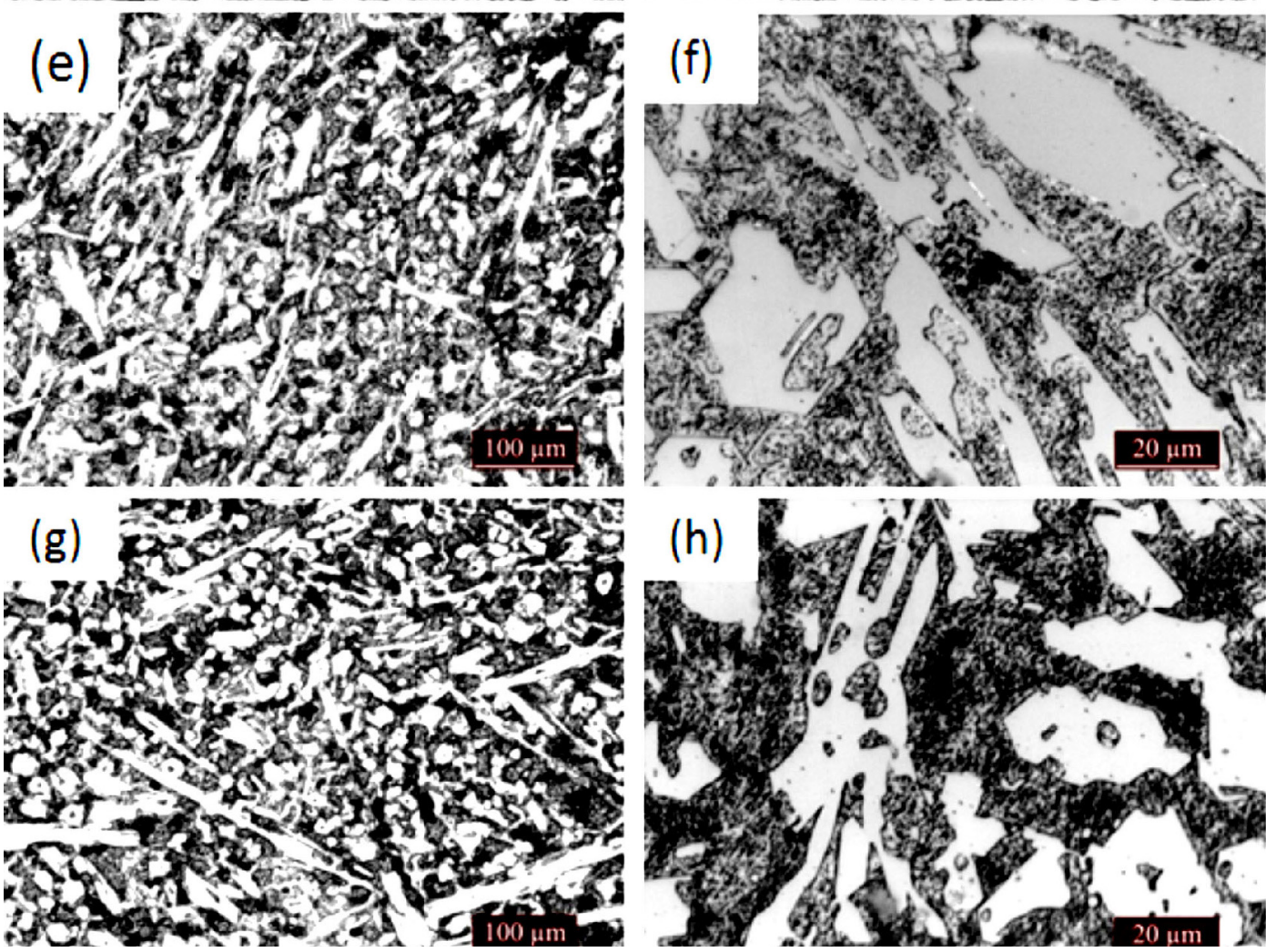

Fig. 9: Microstructure of as-tempered HCCls: (a), (b) $0 \mathrm{~Hz}$; (c), (d) $30 \mathrm{~Hz}$; (e), (f) $40 \mathrm{~Hz}$ and (g), (h) $50 \mathrm{~Hz}$ 
and as-quenched HCCIs. However, the precipitates of carbides among the eutectic colonies from the as-tempered specimens could be clearly observed, as shown in the magnified images of Fig. 9.

The hardnesses of the as-tempered HCCIs are shown in Fig. 10(a). In comparison with those of the as-quenched HCCIs, a reduction of 2-3 HRC in hardness for the as-tempered HCCIs was found, which is due to the transformation of the matrix from martensite to tempered martensite. After tempering, all the specimens have similar hardness of approximate $64 \mathrm{HRC}$ in spite of the variation of vibration frequency.

The evolution of impact absorbing energy of the as-tempered HCCIs with different vibration frequencies is shown in Fig. 10(b). The impact absorbing energy of the as-tempered HCCIs increased from 3.1 $\mathrm{J}$ for the specimens produced by LFC without vibration to $4 \mathrm{~J}$ for the specimens produced by $\mathrm{LFC}$ with a vibration frequency of $50 \mathrm{HZ}$, which is mainly due to microstructure refinement.
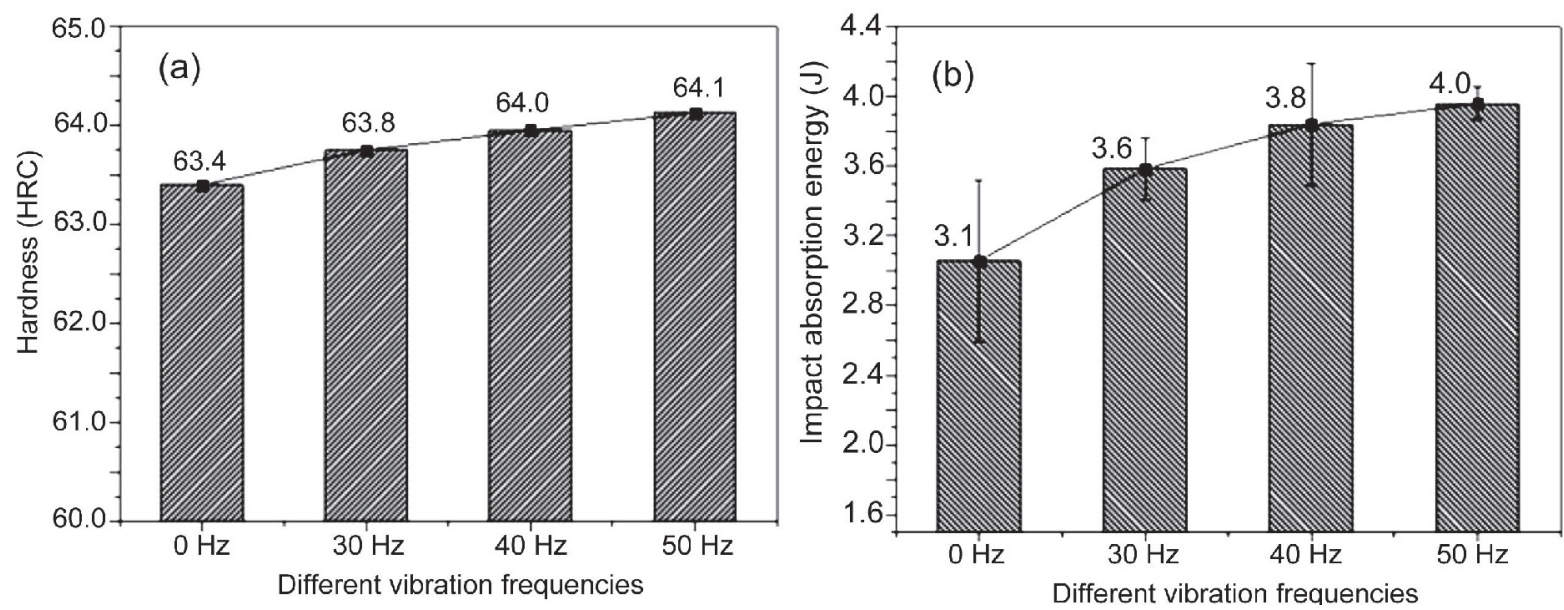

Fig. 10: Influence of different vibration frequencies on hardness (a) and impact absorption energy (b) of as-tempered $\mathrm{HCCls}$

\subsection{Wear resistance of $\mathrm{HCCls}$ after heat treatment}

Figure 11 shows the wear weight loss of the HCCIs after heat treatment under different wear loads. The wear weight losses of the as-tempered HCCIs without vibration show higher values than those of the HCCIs with vibration under both $30 \mathrm{~N}$ and 50 $\mathrm{N}$ loads, indicating that the imposed mechanical vibration during solidification could enhance the wear resistance of the HCCIs. In particular, the HCCIs with mechanical vibration presented evident improvement in wear resistance under higher load, e.g. 50 N. With an increase in vibration frequency, the wear weight loss of the LFC produced HCCIs decreased, suggesting that the wear resistance of the as-tempered HCCIs was enhanced. The improvement of wear resistance could be attributed to microstructure refinement, which increases the impact toughness and thereby reduces the spalling of carbides during the wear process.
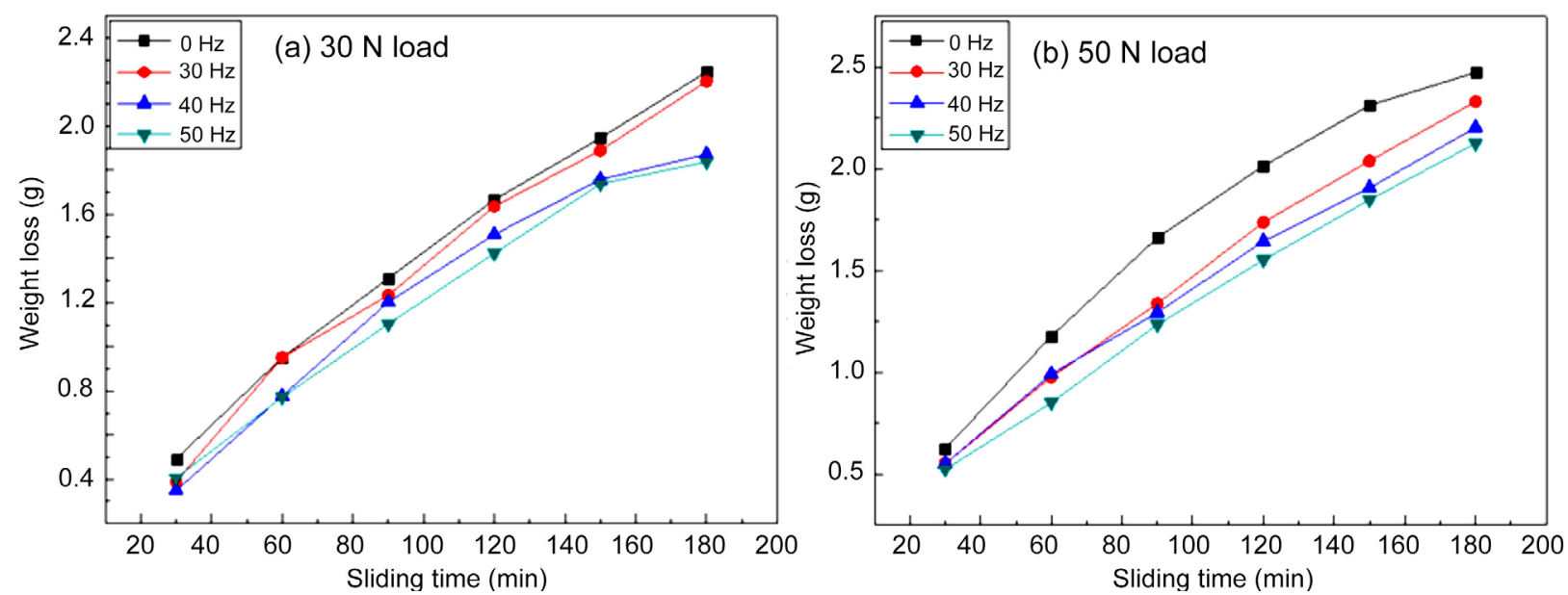

Fig. 11: Wear weight loss of heat treated HCCls under different loads 


\section{Discussions}

The HCCIs in this study have hypereutectic compositions and their solidification includes stable and metastable transformation. The crystal nucleus of the primary carbides initially occur from the melt when the temperature of the molten metal reaches the liquidus line. The carbon atoms of the liquid metal surrounding the primary carbides crystal nucleus diffuse and accumulate toward the crystal nucleus, which result in the constituent fluctuations of the molten metal. In addition, a great deal of gas is produced from the vaporized foam during LFC process, which could also cause the constituent fluctuation of the molten metal. In particular, the imposition of vibration would further increase the constituent fluctuation through accelerating the gas escaping. These aspects would favor the nucleation of the primary carbides and lead to the refinement of primary carbides, as observed from the morphologies of the primary carbides shown in Fig. 4.

During the subsequent eutectic reaction, the nucleation and growth of austenite on the primary carbide surface occurred and it quickly closed around the primary carbide. Therefore, the interval space among the primary carbides determined the size of eutectic colonies, which also means that the refinement of the primary carbides could further induce the refinement of the eutectic colonies. Similar results had been reported for the solidification of ductile cast iron, where the constituent fluctuation induced by mechanical vibration promoted the nucleation of graphite nodules ${ }^{[2]}$.

In addition to accelerating the constituent fluctuation, three other aspects would also affect the transformation of the microstructure when the mechanical vibration was imposed during solidification process of HCCIs in LFC process. The first one is the "drifting" phenomenon of the heterogeneous nucleated grains from the cold mold wall due to mechanical vibration, which increased the amounts of the crystal nucleus in the molten metal. The secondary aspect corresponds to the perturbation of mechanical vibration on the liquid molten metal, which resulted in the interruption of the dendrite growth. Subsequently, more grains would be produced through crashing and abrasion of the formed dendrites. The third aspect is related to the settlement of the formed crystalline from the top of the liquid level down to the inside of the molten metal because of the density difference between the formed solid crystalline and the liquid molten metal. This would introduce more crystal nucleii inside the molten metal. In summary, the above three aspects resulting from mechanical vibration would favor to grain refinement of the LFC produced HCCIs.

After solidification, the morphologies of both the primary carbide and the eutectic carbides could not change in the subsequent heat treatment process. The heat treatment process only affects the microstructure of the matrix. As shown in Fig. 6 and Fig. 9, an evolution from austenite, martensite to tempered martensite for the matrix was identified with respect to the ascast, as-quenched and as-tempered conditions. However, since most carbides remained unchanged, the variations of matrix microstructure showed only a slight effect on the mechanical properties including hardness and impact toughness.

Wear resistance depends on the hardness and the impact toughness. Although the improvement of hardness was not evident, the slight increase of impact absorption energy could play an important role in the improvement of the wear resistance for the LFC-produced HCCIs. In fact, the HCCIs were rather brittle materials in wear resistant applications. In spite of the slight improvement in the absolute value of impact absorption energy, the relative value of the impact absorption could reach approximately $30 \%$, as shown in Fig. 10, which reduced the spalling of carbides during the abrasive wear process and thereby enhanced their wear resistance. In addition, the more isotropic of the primary carbides induced by mechanical vibration would favor the improvement of wear resistance.

\section{Conclusions}

(1) The as-cast HCCIs produced by LFC with different vibration frequencies mainly consisted of primary carbides and eutectic colonies. With an increase in the vibration frequency, the primary carbides and eutectic colonies were refined gradually. However, the hardness showed a slight increase with an increase in the vibration frequency.

(2) After quenching and tempering, the morphologies of the eutectic colonies changed and the precipitates of carbides from the as-tempered specimens were found. The hardness of the asquenched and as-tempered HCCIs was improved compared to that of the as-cast HCCIs. However, the hardness showed a slight variation in spite of the increase of vibration frequency. In contrast, impact absorbing energy was improved with an increase in the vibration frequency

(3) The wear resistance of the heat treated HCCIs with vibration under different loads was improved compared to those without vibration. The wear weight loss decreased with an increase in the vibration frequency.

\section{References}

[1] Shivkumar S, Yao X, and Makhlouf M. Polymer-melt interactions during casting formation in the lost foam process. Scripta Metal. Mater., 1995, 33(1): 39-46.

[2] Xiao Botao, Fan Zitian, Jiang Wenming, et al. Microstructure and Mechanical Properties of Ductile Cast Iron in Lost Foam Casting with Vibration. Journal of Iron and Steel Research, International, 2014, 21(11): 1049-1054.

[3] Mehdi Hejazi M, Divandari M, and Taghaddos E. Effect of copper insert on the microstructure of gray iron produced via lost foam casting. Materials \& Design, 2009, 30(4): 10851092.

[4] Li Fengjun, Shen Houfa and Liu Baicheng. Modeling of mold filling and solidification in lost foam casting. J. Materials Science and Technology, 2003, 19(5): 395-397.

[5] Xiao Botao, Fan Zitian, Liu Xinwang. Grain refinement and hardness of grey cast iron in lost foam casting with mechanical vibration. Metalurgia International, 2013, 18(3): 16-18.

[6] Zhao Zhong, Fan Zitian, Jiang Wenming, et al. Microstructural evolution of $\mathrm{Mg}_{9} \mathrm{AlZnY}$ alloy with vibration in lost foam casting 
during semi-solid isothermal heat treatment. Transactions of Nonferrous Metals Society of China, 2010, 20(3): 768-773.

[7] Li Jiqiang, Fan Zitian, Wang Yuanqing, et al. Effects of vibration and alloying on microstructure and properties of AZ91D magnesium alloy via lost foam casting. The Chinese Journal of Nonferrous Metals, 2007, 17(7): 1047-1052. (In Chinese)

[8] Abramov A, Abramov O, Bulgakov V, et al. Solidification of aluminum alloys under ultrasonic irradiation using water-cooled resonator. Materials Letter, 1998 37(1-2): 27-34.

[9] Abu-Dheir Numan, Khraisheh Marwan, Saito Kozo, et al. Silicon morphology modification in the eutectic Al-Si alloy using mechanical mold vibration. Materials Science and Engineering A, 2005, 393: 109-117.

[10] Kocatepe Kadir. Effect of low frequency vibration on porosity of LM25 and LM6 alloys. Materials \& Design, 2007, 28(6): 17671775.

[11] Zhi Xiaohui, Xing Jiandong, Fu Hanguang, et al. Effect of niobium on the as-cast microstructure of hypereutectic high chromium cast iron. Materials Letters, 2008, 62: 857-860.

[12] Zhang Zhiguo, Yang Chengkai, Zhang Peng, et al. Microstructure and wear resistance of high chromium cast iron containing niobium. China Foundry, 2014,11(3): 179-184.

[13] Tabrett C P and Sare I R. Effect of high temperature and subambient treatments on the matrix structure and abrasion resistance of a high-chromium white iron. Scripta Materialia, 1998, 38(12): 1747-1753.

[14] Liu H, Sakamoto M, Nomura M, et al. Abrasion resistance of high $\mathrm{Cr}$ cast irons at an elevated temperature. Wear, 2001, 250: 71-75.

[15] Llewellyn R J, Yick S K and Dolman K F.. Scouring erosion resistance of metallic materials used in slurry pump service. Wear, 2004, 256: 592-599.

[16] Wiengmoon A, Chairuangsri T, Brown A, et al. Microstructural and crystallographical study of carbides in $30 \mathrm{wt} . \% \mathrm{Cr}$ cast irons. Acta Materialia, 2005, 53: 4143-4154.

This work was financially supported by the Science and Technology Plan Project of Guangdong province, China (2015B090926012, 2014B090901001034, 2014YT02C036, 2013B090500106, 2013CX/G18) and the Scientific Research and Innovation Project of Jinan University (No. 21615437). 